\title{
Omphacite Microstructures from a Spanish Eclogite
}

\author{
HERMAN L. M. VAN ROERMUND \\ Mineralogisk-Geologisk Museum, Sarsgaten 1, Oslo 5, Norway
}

(Received October 31, 1983; in final form May 15, 1984)

The microstructures of some naturally deformed clinopyroxenes from the Betic Cordilleras southern Spain are described in some detail. The PT conditions at the time of deformation are estimated to be $12 \mathrm{~kb}$ and $500^{\circ} \mathrm{C}$. Optical and TEM studies indicate that deformation takes place essentially by conservative slip on $\{\mathrm{hk} 0\}$ [001] to produce lattice bending and kinking, whilst minor contributions from dislocation creep occur. Slip is accompanied by extensive grain and kink band boundary migration leading locally to recrystallisation. Additional defect structures are inhomogeneously distributed anti-phase domains, typically of 2 sizes, 0.03 and $0.3-1 \mu \mathrm{m}$.

\section{INTRODUCTION}

An understanding of mechanisms of plate tectonics requires detailed knowledge of the flow behaviour of the major rock forming minerals of the lower crust and upper mantle. Experimental rock deformation and TEM studies have shown that these minerals deform plastically in a number of ways. At temperatures less than about half the melting temperature $\left(T_{m}\right)$, where diffusion is slow, deformation is controlled by the conservative motion of dislocations. At these temperatures deformation may also occur in certain materials, including clinopyroxenes, by mechanical twinning. At high temperatures $\left(>0.5 T_{m}\right)$ diffusion of vacancies and other point defects becomes an important mechanism for deformation, as well as a means of controlling glide.

For particular grain sizes each of these deformation mechanisms can be described in terms of particular flow laws (e.g. Ashby and Verrall, 1977; Schmidt, 1983). However, the large differences in strain rate 
between laboratory studies and natural deformation conditions are a major drawback to extrapolation of laboratory-derived data to natural conditions. Nevertheless, such extrapolations might be justified if naturally deformed minerals exhibit the same microstructures as are seen in laboratory studies. Although much progress has been made concerning quartz, olivine, calcite and mica there is still a lack of detailed microstructural studies of other naturally deformed minerals.

Eclogites are particularly suitable for the study of the mechanical behaviour of clinopyroxenes. Most eclogites contain a mineralogical layering defined by the relative proportions of the major rock forming minerals omphacite (a clinopyroxene), garnet, \pm quartz, \pm orthopyroxene. Clinopyroxenite layers are generally present. The recently improved geothermometric/barometric methods allow accurate estimation of the PT conditions at the time of deformation. Eclogites also typically form at high pressures $(\geqslant 10 \mathrm{~kb})$ and the experimental constraints of high confining pressures to surpress brittle and semi-brittle behaviour are therefore easily satisfied. This paper describes some clinopyroxene microstructures from naturally deformed eclogites and clinopyroxenites of the Betic Cordilleras, southern Spain, using optical and electron microscopy.

\section{GEOLOGICAL SETTING}

The deepest part of the Betic Cordilleras, the orogenic zone of Alpine age in southern Spain, are exposed in the Sierra Nevada and Sierra de los Filabres. The Alpine metamorphic history of the S.E. Sierra de los Filabres has been described by Roever \& Nijhuis (1964). Puga (1977) recognised eclogitised ophiolites among the early products of Alpine metamorphism in the Sierra Nevada. In the eastern Sierra de los Filabres, the Bédar Nappe consists of mesozoic rocks, which discordantly cover a base of polymetamorphic graphite schists and subordinate marbles, intruded by a 270 Ma-old tourmaline-granite. Alpine deformation and recrystallisation transformed the granite into a tourmaline-(augen)-gneiss. Within and along its border a number of pyroxenites and lens-shaped, partly eclogitised, hedenbergite skarns are present (Helmers, 1982). The studied samples are taken from these eclogitised skarns and pyroxenites. For a detailed description of field relations, mineralogy and chemistry the reader is referred to Helmers (1984). 


\section{MATERIAL AND TECHNIQUES}

The studied samples Hel 757 and Bic 2057 consist of coarse grained clinopyroxenite in rhythmic alteration with epidotites in Bic 2057 and with minor amounts of albite (5\%) in Hel 757. Excess quartz is available in both rock types elsewhere. Electron microprobe analyses were carried out using a ARL-EMX electron microprobe fitted with a Link energy dispersive system at the Mineralogical-Geological Museum, Oslo. The analyses of clinopyroxenes are given in table 1 .

\section{TABLE I}

Electron microprobe analyses and calculated structural formulae, based on 6 oxygens, of clinopyroxenes. (A, Hel 757; B, Bic 2057)

\begin{tabular}{lrr}
\hline & $\mathrm{A}$ & $\mathrm{B}$ \\
$\mathrm{SiO}_{2}$ & 54.67 & 56.41 \\
$\mathrm{Al}_{2} \mathrm{O}_{3}$ & 7.18 & 10.80 \\
$\mathrm{FeO}$ & 6.09 & 5.25 \\
$\mathrm{MnO}$ & .22 & - \\
$\mathrm{MgO}$ & 9.66 & 7.93 \\
$\mathrm{CaO}$ & 15.34 & 12.71 \\
$\mathrm{Na}_{2} \mathrm{O}$ & 5.62 & 7.01 \\
$\mathrm{Total}$ & 98.78 & 100.11 \\
$\mathrm{Si}$ & & \\
$\mathrm{Al}$ & 2.00 & 2.00 \\
$\mathrm{Fe}$ & .31 & .45 \\
$\mathrm{Mn}$ & .19 & .16 \\
$\mathrm{Mg}$ & .01 & - \\
$\mathrm{Ca}$ & .53 & .42 \\
$\mathrm{Na}$ & .60 & .48 \\
\hline
\end{tabular}

Suitable areas were located in thin sections by optical microscopy and subsequent thinned by ion-bombardment. Thinned samples have been examined using a Jeol 200A electron microscope at the Physics Department, University of Oslo, Norway.

\section{OPTICAL MICROSTRUCTURE}

The overall appearance of the clinopyroxenite layers/lenses is illustrated in Figure 1. They show randomly oriented deformed clinopyroxenes 


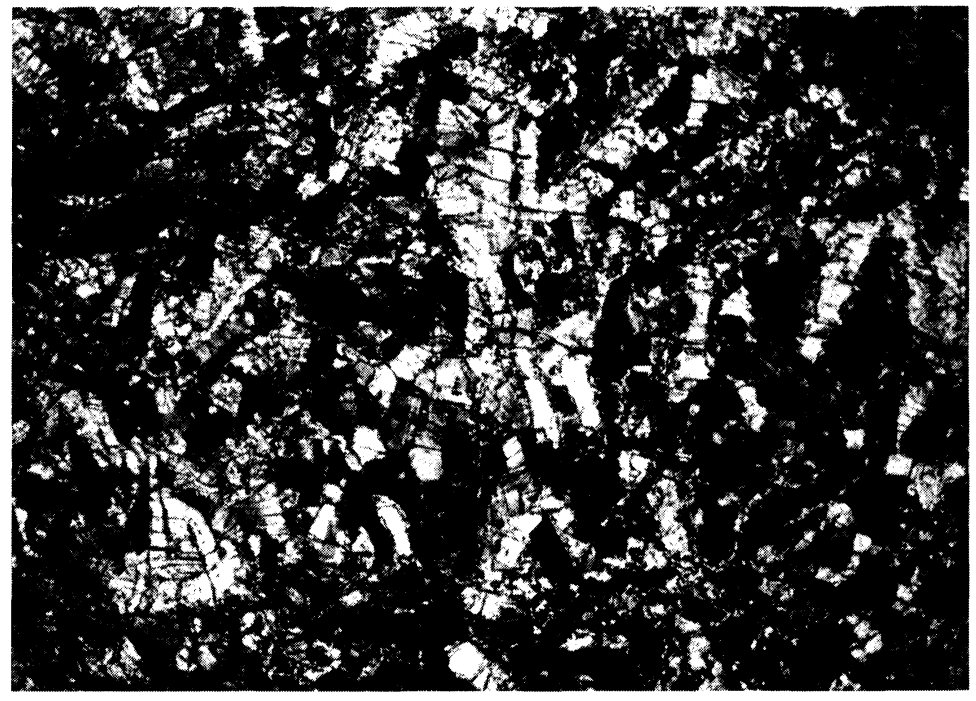

FIGURE 1 Overall microstructure of the clinopyroxenite showing randomly oriented, severely kinked, omphacites. Notice that approximately all N-S boundaries are serrated kink band boundaries subdividing the much larger omphacites. (Magnification 25X).

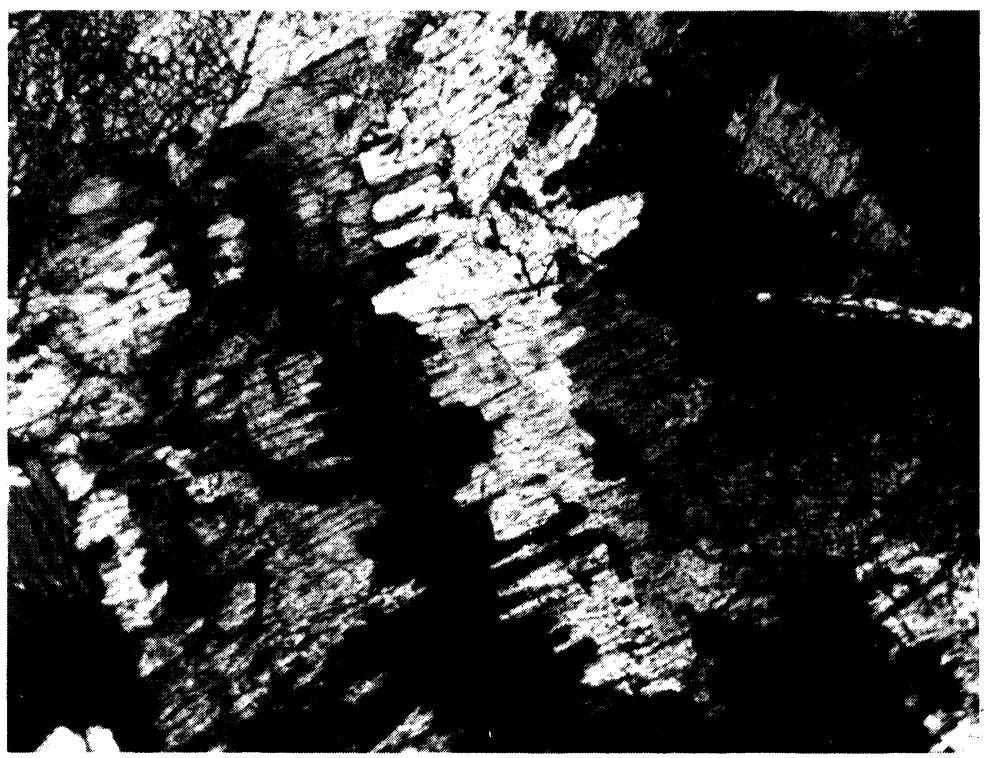

FIGURE 2 Serrated kink band boundaries in clinopyroxene (optical micrograph, magnification 160X). 


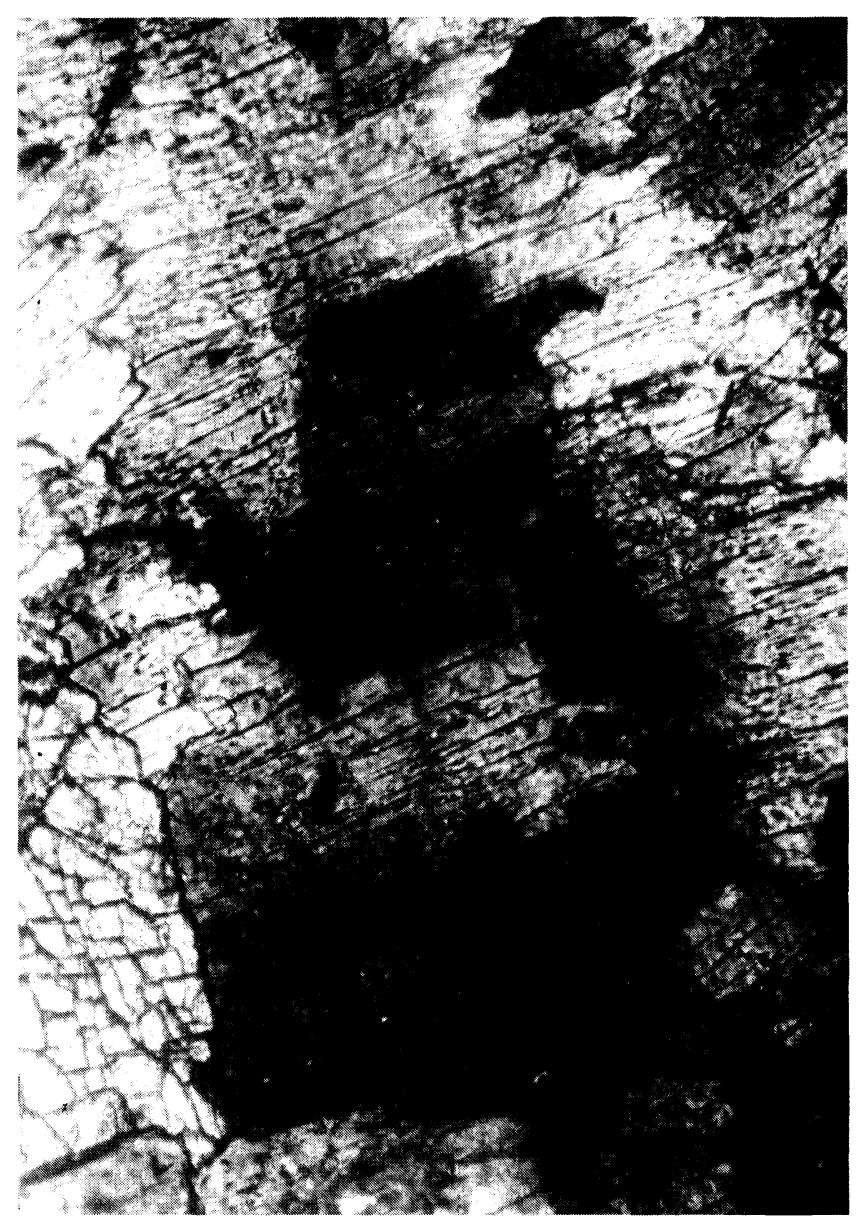

FIGURE 3 Subgrains in clinopyroxene (optical micrograph, magnification 250X).

(sizes 1-5 mm, aspect ratios up to 1:5) having strongly serrated grain boundaries. Internal defect structures reveal mostly kinks but undulatory extinction, subgrains, deformation lamellae and a small number of microtwins have also been observed. The geometry of the kink band boundaries (KBB's) can be sharp but are most commonly strongly serrated due to KBB migration. The latter microstructure tends to obscure the original kink geometry. The serrations tend to be elongated and bounded by planes of the type $\{\mathrm{hk} 0\}$ on one or both 
sides of the boundary (Fig. 2). The wavelength of the serrations is irregular. Locally, serrations grade into discrete new grains as low angle boundaries form behind them and then increase in misorientation, presumably during progressive deformation (bulge nucleation model of $\mathrm{Hu}(1963)$ ). Within one clinopyroxene grain KBB's can be parallel and oriented at high angles $\left(45-90^{\circ}\right)$ to [001] but more commonly KBB's have a divergent appearance whilst individual KBB's often terminate or are offset along $\{\mathrm{hk} 0\}$. The latter microstructure gradually grades into divergent anastomosing patterns which are due to syntectonic polygonisation of bent crystals. Such polygonised "folds" often have a check subgrain pattern since the subgrain boundaries are either oriented parallel to $\{\mathrm{hk} 0\}$ or subperpendicular to [001] (Fig. 3).

There appears to be no constant KBB spacing, neither is there a favoured angle of bending across the KBB. High angle KBB's $\left(>10^{\circ}\right)$ have led to recrystallisation giving rise to elongated grains parallel to the KBB's. This typical microsctructure, accompanied by extensive grain and KBB migration, locally dominates the texture (Fig. 1). Kinkaxes have a great-circle distribution perpendicular to [001]. This and the orientation on either side of individual KBB's indicate that $\{\mathrm{hk} 0\}$ [001] slip is the dominant glide system.

\section{TEM OBSERVATIONS}

\section{Dislocation arrays}

Although tangled dislocation walls are common, most of the subboundaries have a relatively simple structure and consist of parallel arrays of dislocations. Typical examples of this microstructure are illustrated in figure 4. Contrast analyses using reflections of the type $g=220$, $\mathbf{g}=110$ and $\mathbf{g}=210$ reveal no or only residual contrast indicating that they are edge, screw or mixed dislocations with Burgers vector $\mathbf{b}=[001]$. Besides these simple dislocation subboundaries more complex structures have been observed but only on a minor scale (Fig. 5). They consist of networks composed of two crossing sets of parallel dislocations which are not simple twist boundaries since nodes at the points of intersection have been observed. By analogy with similar microstructures in naturally deformed omphacites from eclogites of the Swedish Caledonides these complex subboundaries are inferred to have additional Burgers vectors $\frac{1}{2}\langle 110\rangle$ and $\frac{1}{2}\langle 112\rangle$ (van Roermund and 


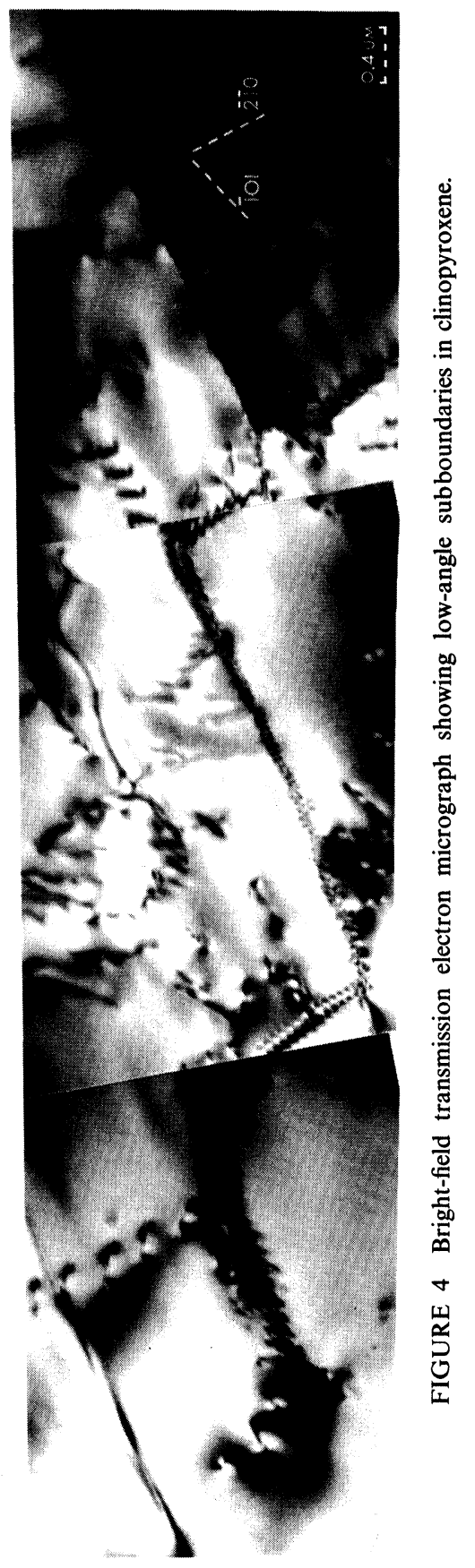




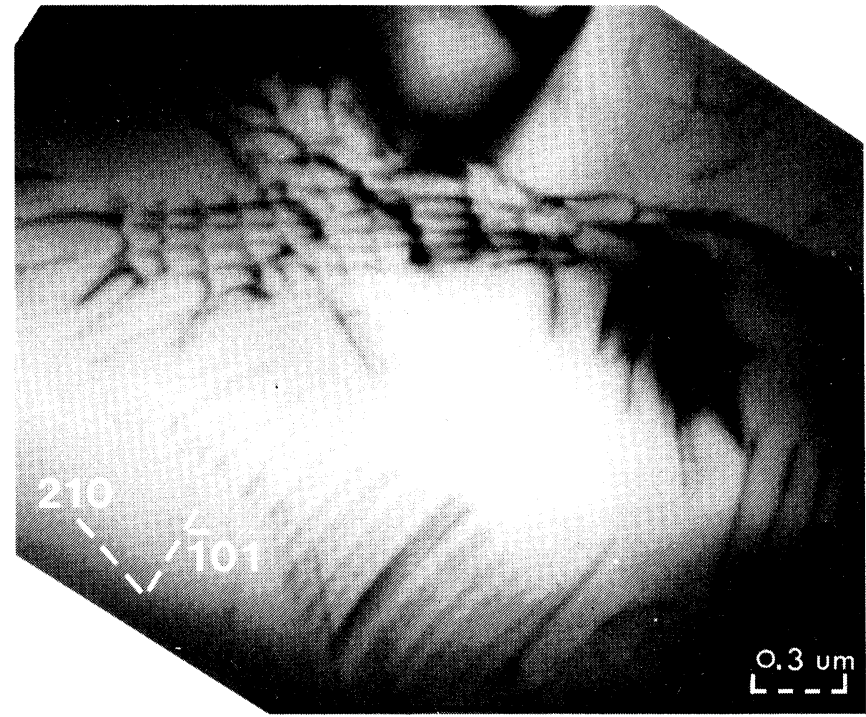

FIGURE 5 Bright field transmission electron micrograph showing complex subboundary in clinopyroxene.

Boland, 1981). Due to their infrequent occurrence no information about their spatial orientation is available.

\section{Free dislocations}

The distribution of free dislocations within the subgrains is very heterogeneous but is always $\left\langle 10^{9} \mathrm{~cm}^{-2}\right.$. In all samples subgrain domains contain isolated dislocations, dislocation tangles, and elongated loops as well as minor evidence for the rearrangement of dislocations into lower energy configurations indicating recovery and/or creep. Contrast analyses using reflections of the type $\mathbf{g}=220,110$ and 210 give no or only residual contrasts indicating that the majority of these free dislocations are edge, screw or mixed dislocations with Burgers vector [001].

\section{Anti-phase domains}

Anti-phase domains (APD's) are present in the omphacites. APD's are formed during cooling when the phase boundary between $C 2 / c$ and 


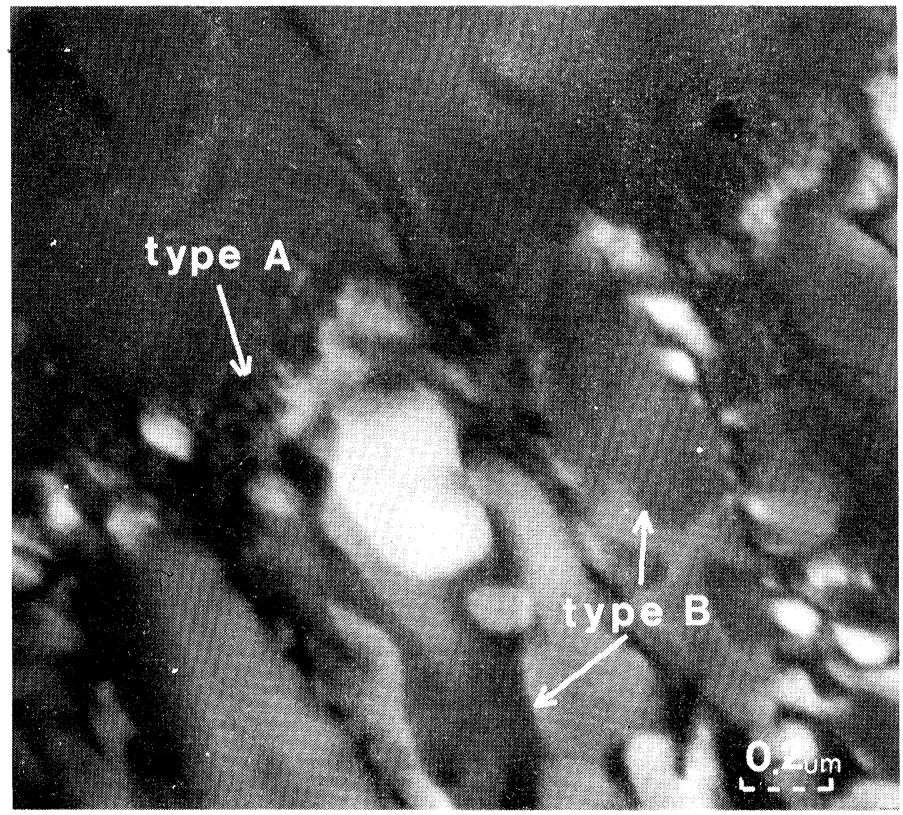

FIGURE 6 Transmission electron micrograph showing smoothly curved anti-phase domains of two generations (type A and B), associated with low angle subboundaries in clinopyroxene, $\mathbf{g}=100$. See text for further details.

$P 2 / n$ crystal structures is crossed (Carpenter, 1978). APD boundaries are visible if reflections of the type $h+k=$ odd are used (Phakey and Ghose, 1973).

The distribution of APD's is inhomogeneous and the interface between untransformed $(C 2 / c)$ and transformed $(P 2 / n)$ domains is illustrated in figure 6. APD's are broadly equidimensional whilst size distribution studies indicate two ranges differing by one order of magnitude in size i.e. type A $(0.03 \mu \mathrm{m})$ and type $B(0.3-1 \mu \mathrm{m})$. Type A occurs at the interface between transformed and untransformed areas as well as along dislocation walls whilst type B generally is confined to the subgrain areas (Fig. 6). The latter is inferred to represent coarsened type A domains whilst coarsening of type A domains at dislocation walls is prevented by APD boundary pinning. This microstructure thus indicates that in the low temperature omphacites APD boundaries are the result of nucleation during cooling and cannot be regarded as the 
metastable nucleation of $C 2 / c$ domains within $P 2 / n$ domains as suggested by Champness (1973).

\section{Maximum conditions of clinopyroxene deformation}

The following methods have been used to estimate the physical conditions of eclogite formation in the surrounding rocks (Helmers, 1984).

i) The thermal and compositional dependence of the $\mathrm{Fe}^{2+} / \mathrm{MG}$ distribution coefficient between garnet and clinopyroxene (Ellis and Green, 1979).

ii) The $P-T$ dependence of the jadeite content of omphacite (Gasperic and Lindsley, 1980).

Intersection of these curves defines temperatures and minimum pressures around $12 \mathrm{~kb}$ and $500^{\circ} \mathrm{C}$ which reflect the maximum conditions of the deformation.

\section{DISCUSSION}

Recent experimental studies have demonstrated a prominent change in the mechanical behaviour of single clinopyroxene crystals and polycrystalline aggregates (Avé Lallement, 1978; Kollé and Blacic, 1983; Kirby and Kronenberg, 1983). At low temperatures and high strain rates and at confining pressures $>10 \mathrm{~kb}$ stress-strain curves are remarkably insensitive to these parameters and deformation occurs by mechanical twinning and/or slip in the $\langle c\rangle$ direction on $\{\mathrm{hk} 0\}$ slip bands. At higher temperatures and lower strain rates the steady state strength is sensitive to temperature and the imposed strain rate. Within this high temperature regime samples deform by climb controlled dislocation creep. Preliminary optical and TEM studies on these materials reveal subgrains and recrystallised new grains but analyses of the operative slip systems have so far not been performed. However, clinopyroxenes (omphacites) deformed in nature within the high temperature regime reveal [001], $\frac{1}{2}\langle 110\rangle$, and $\frac{1}{2}\langle 112\rangle$ Burgers vectors (van Roermund and Boland, 1981). At the time of deformation the latter clinopyroxenes have a $C 2 / c$ crystal structure which is identical to that of the experimentally deformed ones. Nevertheless many clinopyroxenes in nature (low temperature omphacites) appear to have a $P 2 / n$ crystal structure. No experiments have so far been performed with 
$P 2 / n$ clinopyroxenes. But it is likely that the difference in the crystal structure will effect the mechanical behaviour of clinopyroxenes since the active $\frac{1}{2}\langle 112\rangle$ Burgers vector in the $C 2 / c$ structure becomes replaced by the much longer $\langle 111\rangle$ in the $P 2 / n$ structure (Boland, 1980).

The clinopyroxene microstructures described in this paper indicate that under the inferred conditions of natural deformation $\left(12 \mathrm{~kb}, 500^{\circ} \mathrm{C}\right)$ the clinopyroxenes behave according to the transition zone model in which $\{\mathrm{hk} 0\}$ [001] slip, controlled by lattice resistance, is replaced by climb controlled dislocation glide. The microstructures clearly demonstrate that recovery processes are assisted by strain-induced grain and kink band boundary migration. Extensive recrystallisation is absent. The latter is probably due to the lower strain rates of natural deformation but can also be explained by assuming minor amounts of water facilitating glide and climb. Fluids in the crystal structure appear to affect the mechanical properties of clinopyroxenes in the high temperature regime (water weakening effect, Avé Lallement, 1978).

\section{Acknowledgements}

I wish to thank Henk Helmers, Geological Institute, University of Amsterdam for donation of the samples and fruitful discussion on the geological setting. Financial support was given by the Royal Norwegian Council for Scientific and Industrial Research in the form of a post doctoral fellowship at the Mineralogical Geological Museum, Oslo. Support of Bill Griffin and Jon Gjønnes was indispensable and therefore gratefully acknowledged.

\section{References}

Ashby, M. F. and Verral, R. A. Micromechanisms of flow and fracture and their relevance to the rheology of the upper mantle. Phil. Trans. R. Soc. London A. 288, 59-95 (1977).

Avé Lallement, H. G. Experimental deformation of diopside and websterite. Tectonophysics, 48, 1-27 (1978).

Boland, J. N. Electron microscopy of mineral phase transformations in metamorphic reactions. Proc. 7th Eur. Congr. Electr. Microsc., 1, 444-451 (1980).

Carpenter, M. A. Kinetic control of ordering and exsolution in omphacite. Contr. Min. Petrol. 67, 17-24 (1978).

Champness, P. E. Speculation on an order-disorder transformation in omphacite. Am. Min. 58, 540-545 (1973).

Ellis, D. J. and Green, D. H. An experimental study of the effect of Ca upon garnetclinopyroxene $\mathrm{Fe}-\mathrm{Mg}$ exchange equilibria. Contr. Min. Petrol. 71, 13-22 (1979).

Gasperic, T. and Lindsley, D. H. Phase equilibria at high pressure of pyroxenes containing monovalent and trivalent ions. In: Prewitt, C. (ed.) Pyroxenes: Reviews in Mineralogy 7, Min. Soc. Am., Washington: 309-339 (1980).

Helmers, H. Eclogitisation of hedenbergite skarns in the Sierra de los Filabres, S.E. Spain. Terra Cognita, 2, 320 (1982). 
Helmers, H. Eclogitisation of hedenbergite skarns in the Sierra de los Filabres, S.E. Spain. Proc. Eclogite Conference Cl-Ferrand 1982: In press (1984).

$\mathrm{Hu}, \mathrm{H}$. Annealing of silicon-iron single crystals. In: Himmel, W. (ed.) Recovery and recrystallisation of metals. Wiley-Int. New-York: 311-362 (1963).

Kirby, S. H. and Kronenberg, A. K. Deformation of clinopyroxenite: evidence for a transition in flow mechanics and semi-brittle behaviour. J. Geoph. Res.: 89, 3177-3192 (1984).

Kollé, J. J. and Blacic, J. D. Deformatıon of single crystal clinopyroxenes: 2. Dislocation controlled flow processes in hedenbergite. J. Geoph. Res. 88, 2381-2393 (1983).

Phakey, P. P. and Ghose, S. Direct observations of anti-phase domain structure in omphacite. Cont. Min. Petrol. 39, 239-245 (1973).

Puga, E. Sur l'existence dans le complexe de la Sierra Nevada (Cordillères Bétiques, Espagne $d u$ Sud) d'eclogites et sur leur origine probable à partir d'une croûte océanique mésozoique. C. R. Acad. Sc. Paris. 285. Série D: 1378-1382 (1977).

Roermund, H. L. M. van and Boland, J. N. The dislocation substructures of naturally deformed omphacites. Tectonophysics, 78, 403-418 (1981).

Roever, W. P. de and Nijhuis, H. J. Plurifacial alpine metamorphism in the Eastern Betic Cordilleras (SE Spain), with special references to the genesis of glaucophane. Geol. Rundschau. 53, 324-336 (1964).

Schmid, S. M. Microfabric studies as indicators of deformation mechanisms and flow laws operative in mountain building. In: Hsu, K. J. (ed.) Mountain building processes. Acas. Press, Inc. USA: 95-110 (1983). 